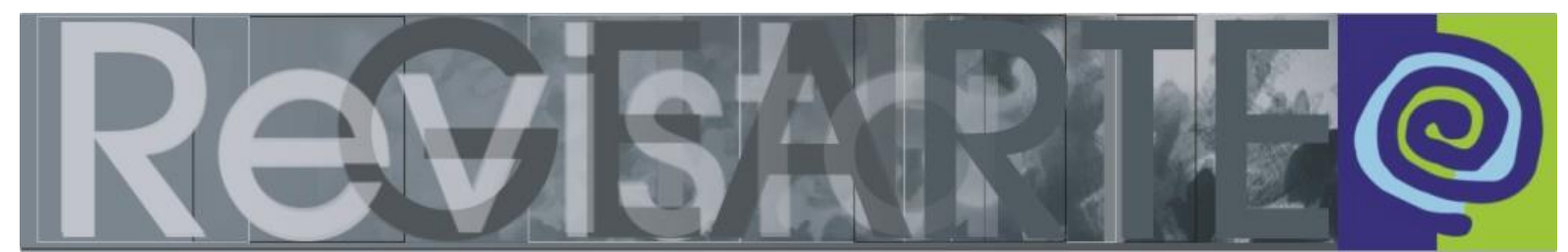

ISSN 2357-9854 | e-ISSN 2596-3198 (online)

\title{
La artesanía como forma de supervivencia. Una historia de vida en tiempos de la postguerra española
}

\author{
María José Delgado Corredera \\ (Universidad de Málaga — UMA, Málaga, España)
}

\begin{abstract}
RESUMEN - La artesanía como forma de supervivencia. Una historia de vida en tiempos de la posguerra española - Corre el año 1947. La guerra civil ha dejado a su paso dolor, hambre y pobreza. Electra a sus once años, al igual que los hermanos y hermanas supervivientes, cada día vive la artesanía del duro y hostil esparto como medio de supervivencia familiar. No puede ir a la escuela, su mayor ilusión, y devana sueños en su mente mientras elabora con sus pequeños dedos capachas para prensa de aceite, esteras para entradas de casuchas o salidas de patios pedregosos. Presentamos las historias de vida entrelazadas con la artesanía como forma de encontrar significado educativo en ambas. Cómo se construye una identidad y cómo la artesanía puede ser vivenciada como algo habitual que se aprende y proporciona supervivencia. Concluimos viendo las implicaciones que la artesanía genera e impulsa en Electra para su futuro como mujer.
\end{abstract}

PALABRAS CLAVE

Artesanía. Educación. Esparto. Historia de Vida. Identidad.

RESUMO - A artesania como forma de sobrevivência. Uma história de vida nos tempos do pós-guerra espanhola - O ano é 1947. A guerra civil deixou para trás dor, fome e pobreza. Electra aos onze anos de idade, como os irmãos e irmãs sobreviventes, experimenta a arte do esparto resistente e hostil todos os dias como um meio de sobrevivência familiar. Não pode ir à escola, sua maior ilusão, e acalenta seus sonhos enquanto faz com os dedinhos capas para prensa de óleo, tapetes para entradas de choupanas ou saídas de pátios pedregosos. Apresentamos histórias de vida entrelaçadas com a artesania como forma de encontrar um sentido educacional em ambos. Como construir uma identidade e como a artesania pode ser vivenciada como algo que se aprende e que proporciona sobrevivência. Concluímos examinando as implicações que a artesania gera e promove em Electra para seu futuro como mulher.

\section{PALAVRAS-CHAVE}

Trabalhos manuais. Educação. Esparto. História de vida. Identidade.

ABSTRACT - Craftsmanship as survival. A life story in the postwar period of the Spanish Civil War - 1947. The Civil War has left a trail of pain, hunger and poverty. Electra, an elevenyears-old girl, just like her surviving brothers and sisters, experiences every day the hostile and tough esparto as a way to make a living together with her family. Her greatest desire, to go to school, is denied to her, and in her mind she weaves dreams while her little fingers craft oil-press hampers, mats which cover hovel thresholds or outlets to rocky courtyards. We introduce life stories related to craftsmanship as a form to find educational meaning in both fields -the way an identity is built and how crafting can be lived as something habitual, something that can be learned and yields a livelihood. We conclude the implications and impulses generated by craftsmanship in Electra concerning her future as a woman.

\section{KEYWORDS}

Craftsmanship. Education. Esparto. Life Story. Identity. 


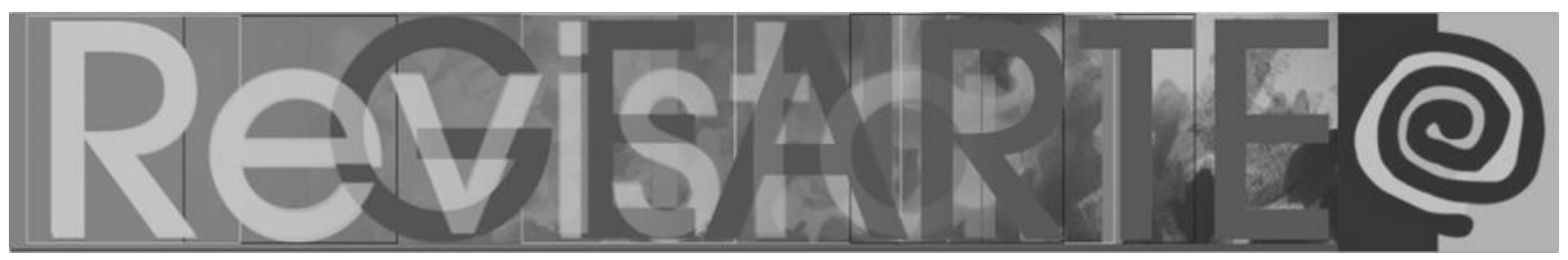

\section{Introducción}

Hablar de artesanía en España es hablar de sus gentes, sus costumbres, sus tradiciones, su manera de vivir en cada época. Hoy lo hacemos tras una mirada a los años cuarenta, en el pueblo de Alhaurín el Grande de Málaga (España) y desde los ojos de una niña de once años llamada Electra, que se sienta cada día en una silla junto a dos de sus hermanos, a trabajar el esparto haciendo "capacho" como forma de subsistencia familiar. La reciente guerra civil ha dejado a su paso dolor, hambre y pobreza. Electra descubre la dura artesanía del esparto desde una vivencia impuesta por su padre, no hallando placer en ello, sino dificultad en mantener el cuerpo quieto en tanto que su deseo de niña la lleva a querer jugar y correr. Sin embargo, como todo proceso artístico, la artesanía conlleva la desconexión de la vida exterior y la liberación de la imaginación favoreciendo un diálogo interno y reflexivo hacia la búsqueda personal. Al igual que Celie en El Color Púrpura, Electra, "al encontrarse con su imaginación, ha descubierto una salida a la opresión" (WALKER, 1982, p.11). Esta búsqueda no lleva solo un hilo conductor; se abre a las distintas facetas o aspectos que darán pie a la lección de una vida futura. Son nuestros recuerdos, nuestros incidentes, nuestra herencia familiar y social los hechos que nos inducen a crear una identidad.

Cuando se trata de supervivencia, el arte parece estar al margen de la vida.

El margen es el lugar de aquellos sentimientos e intuiciones para los que la vida diaria no solo tiene sitio, sino que, muy al contrario, parece reprimirla [...] con el arte, las personas pueden hacerse un espacio para sí mismas y llenarlo de libertad y presencia. (DONOGHUE, 1983, p. 129)

Electra soñará con ir a la escuela, que antes rechazaba, como salida al momento de opresión como niña. Y quizás este impulso sea el que la lleve a partir de ahora a tener el deseo de aprender y enseñar a otras personas en su vida. Con una mirada retrospectiva desde el presente 2020, esta niña-mujer ahora mira con otros ojos su vida y la comprende. Para Woolf (1976, p.72), "al ir haciéndonos mayores, más grande se vuelve también nuestra capacidad de aportar 


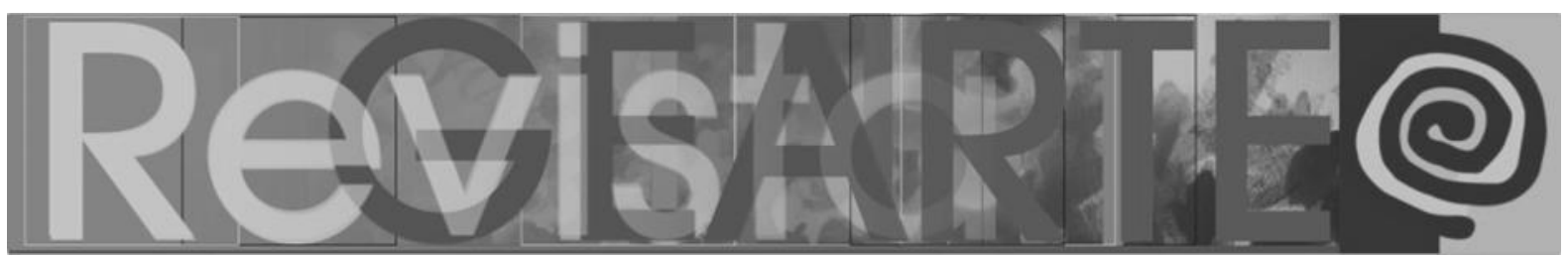

explicaciones por medio de la razón [...] estas explicaciones atemperan la contundencia" del sufrimiento y los golpes que inevitablemente recibimos a lo largo de nuestra vida.

Una gran parte de mi proyecto de vida ha sido lograr comprender la enseñanza y el aprendizaje. Por ello continúo en el proceso de seguir creando mi propio punto de vista dentro de este proyecto, para orientarme en el mundo y conocerme.

\section{Justificación}

\subsection{La artesanía del esparto}

"El esparto es una planta de la familia de las gramíneas, con cañas de unos setenta centímetros de altura y hojas radicales de unos sesenta centímetros de longitud." (SMITH, 2016)

En el documental producido por el ayuntamiento del pueblo de Herencia, en la provincia de Ciudad Real de España, sobre el esparto y la enea y su aplicación de forma artesanal, titulado "Enea y esparto. Artesanía campesina", nos narra el autor Jesús Díaz-Pavón González-Sánchez (2014), monitor de la Universidad Popular de dicho pueblo, que el esparto crece espontáneamente en terrenos semiáridos y pedregosos del Mediterráneo occidental y nos describe esta planta diciendo:

\footnotetext{
Es una hierba perenne, cespitosa, de hojas filiformes y flores hermafroditas. Tiene la base ramificada y forma grandes macollas o vástagos que nacen de un mismo pie. Las hojas son duras y muy tenaces, de un milímetro de diámetro, que suelen estar enrolladas por falta de humedad y que se asemejan a hilos (DÍAZ-PAVÓN, 2014)
}

Antonio Beneto (en DÍAZ-PAVÓN, 2014), artesano espartero, en el mismo documental, explica las diferentes formas de trabajo artesanal, así como los cuidados y preparación que requiere para poder manejarlo: 


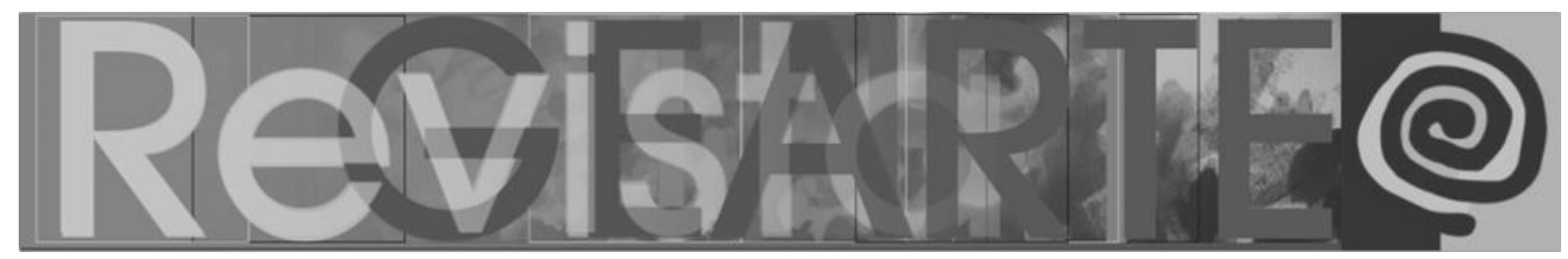

Cuando la planta aún está verde se arranca lo que será la base de los aparejos del esparto. Aunque la recolección puede hacerse durante todo el año, la mejor época para su recogida es de julio a septiembre cuando se encuentra el de mayor calidad. Hay que esperar para que esté "granado", que no esté verdoso para poderlo utilizar en la artesanía. El esparto no se siega. Tiene que recogerse entero, incluida la raíz. Se ayuda el espartero de un palo y enrolla los espartos en este palo para luego tirar de él y arrancarlo, evitando los cortes que podría producirle en las manos ya que es muy agresivo. El espartero tira enérgicamente hacia arriba y va reuniendo pequeños manojos llamados "mañas".

Después de recolectarlo, se eligen las mejores piezas y se colocan en nuevas "mañas" que se atan con un esparto y se colocan a secar al sol hasta que adquieren su color dorado. Posteriormente, el esparto puede ser tratado en seco o bien remojado o machacado. Para trabajarlo una vez seco y dorado hay que remojarlo al menos dos días para que se ablande. Para otras labores, se machacará con una maza sobre un tronco cortado o en una piedra lisa.

Se necesitan pocas herramientas; basta con unas agujas, unas rectas y otras con punta curva, de unos 25 a 30 centímetros para coser de diferentes formas. Pero sobre todo son las manos del espartero su verdadera herramienta con las que va a elaborar la pieza artesana.

Encontramos diferentes formas de trenzar el esparto según los ramales que se cojan y la forma que se desee construir. Así encontramos el trenzado de coleta, de crineja, la pleita, la puntada de pata de gallina y la puntada de abeja que marcan utilidades y estilos distintos. Las piezas que se van haciendo se montan cosiendo con las agujas y un cordelillo elaborado con las fibras desmembradas del propio esparto. De este modo, quedará invisible la puntada al ser del mismo material y color.

A continuación, presentamos algunas fotografías (figuras 1 a 7) de trabajos artesanales con esparto, en una tienda de un mercado ambulante de Málaga. 


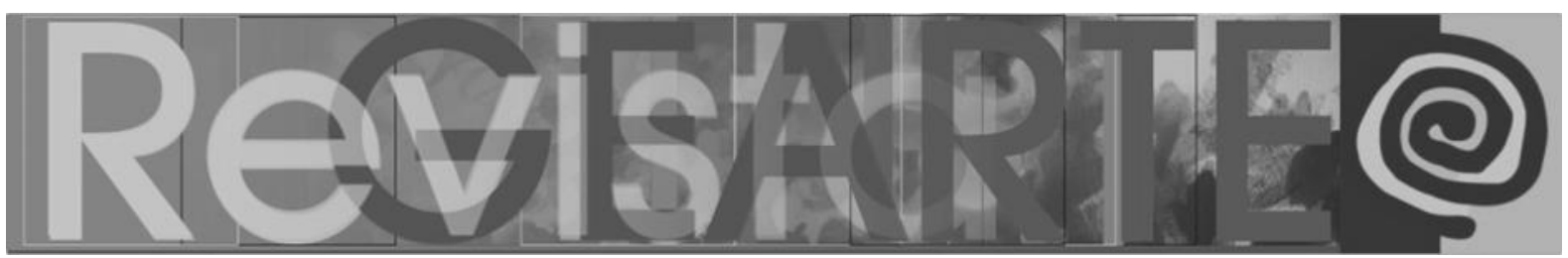

Figura 1 - Lámparas de esparto

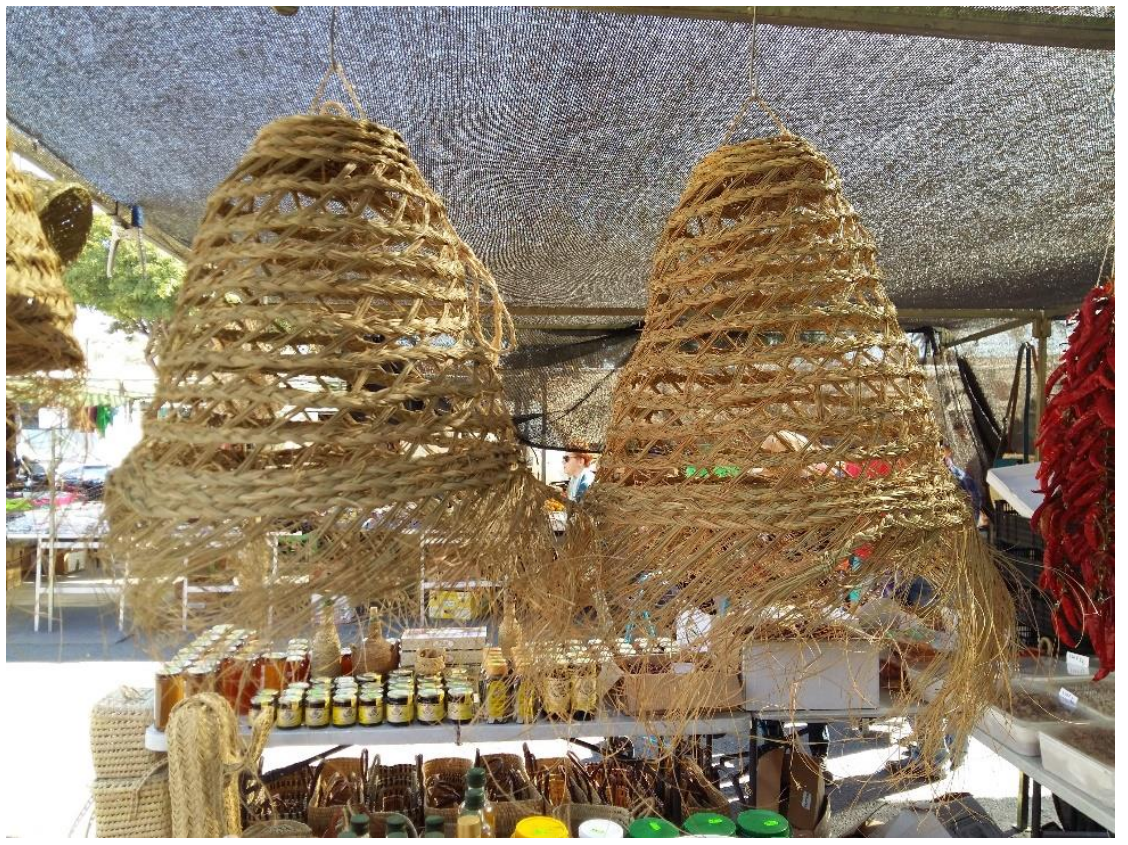

Fuente: Colección personal de la autora. 2020. Mercado ambulante de La Cala del Moral. Málaga

\section{Figura 2 - Lámparas, funda de garrafas y cestos de esparto}

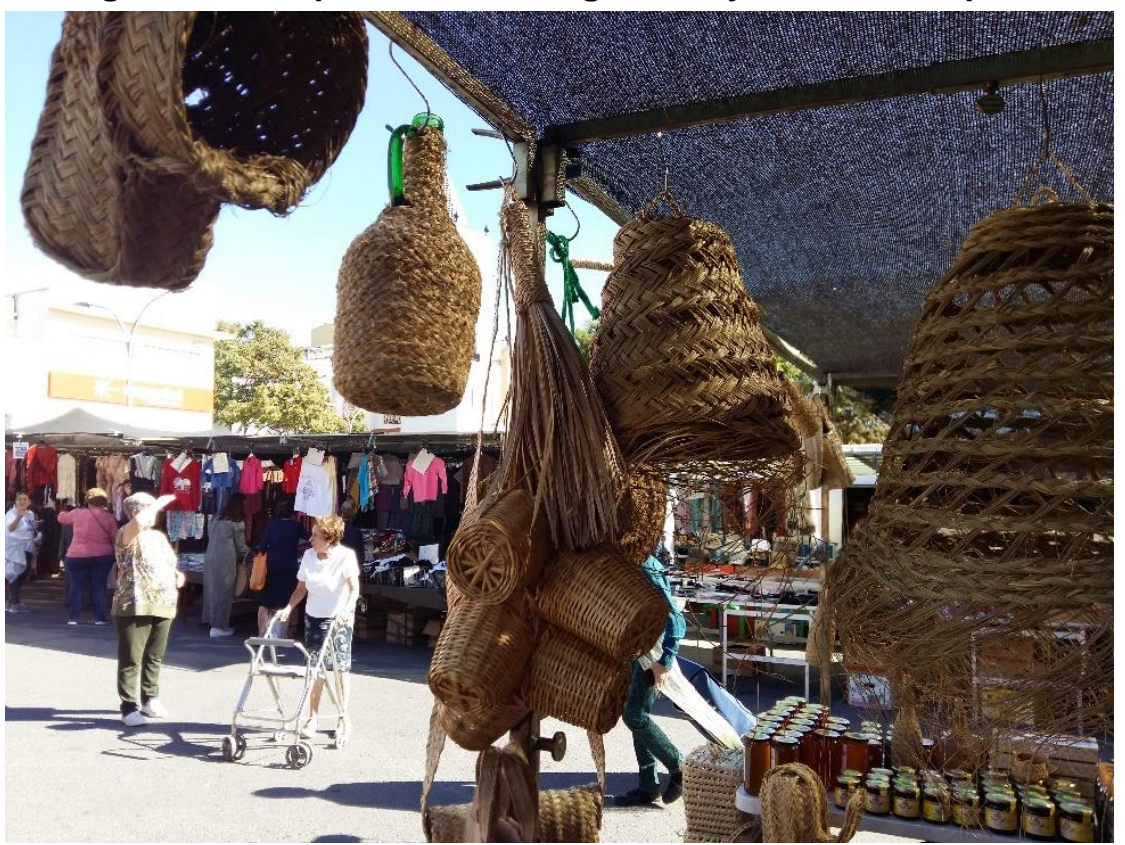

Fuente: Colección personal de la autora, 2020. Mercado ambulante de La Cala del Moral. Málaga.

Una historia de vida en tiempos de la postguerra española.

Revista GEARTE, Porto Alegre, v. 7, n. 3, p. 510-535, set./dez. 2020.

Disponível em: http://seer.ufrgs.br/gearte 


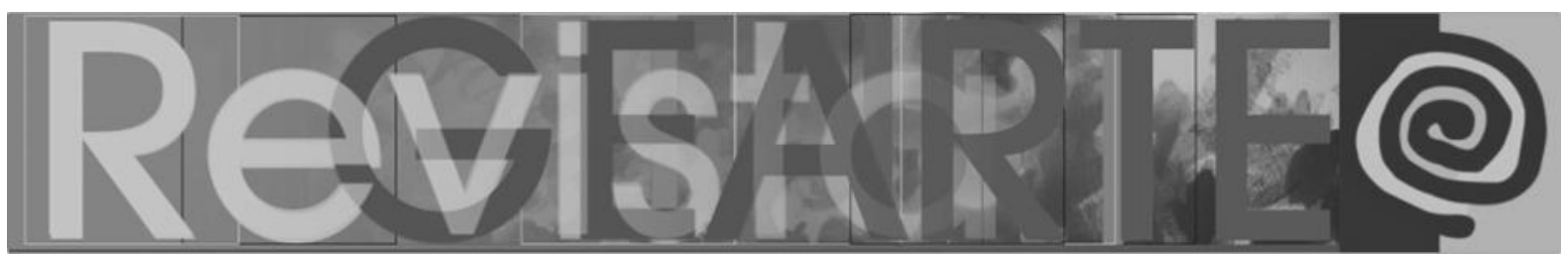

\section{Figura 3 - Cestería de pleita con esparto}

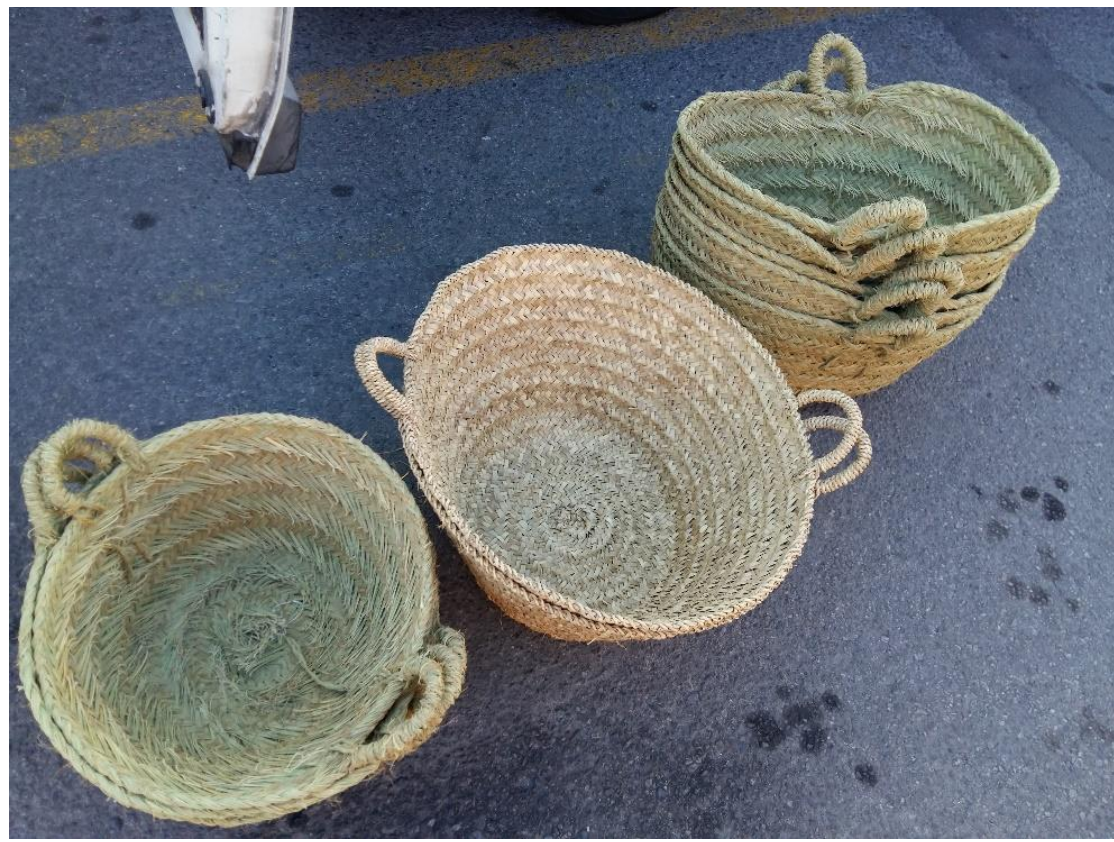

Fuente: Colección personal de la autora, 2020. Mercado ambulante de La Cala del Moral. Málaga.

\section{Figura 4 - Cestería de esparto y pleita}

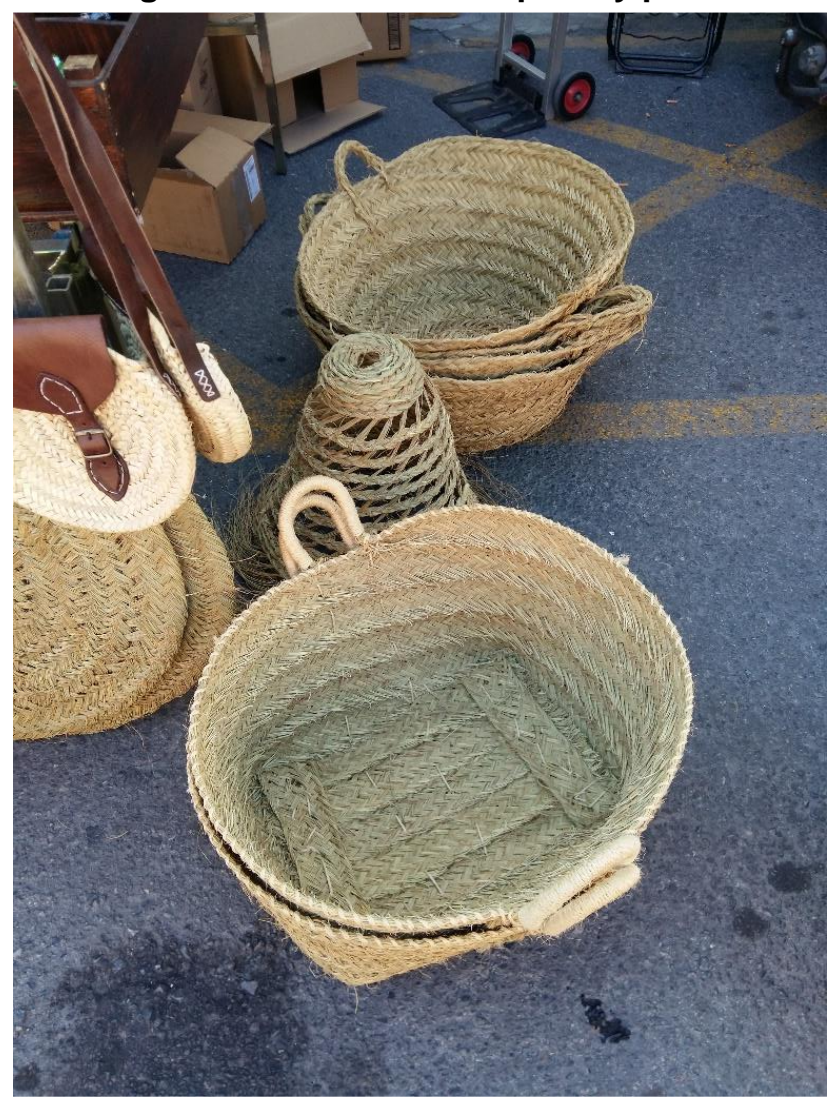

Fuente: Colección personal de la autora, 2020. Mercado ambulante de La Cala del Moral. Málaga.

Una historia de vida en tiempos de la postguerra española.

Revista GEARTE, Porto Alegre, v. 7, n. 3, p. 510-535, set./dez. 2020.

Disponível em: http://seer.ufrgs.br/gearte 


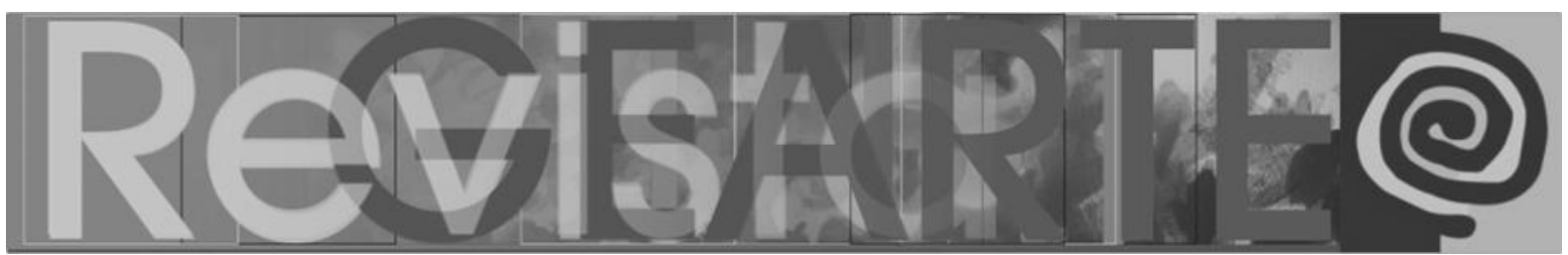

Figura 5 - Estera de esparto

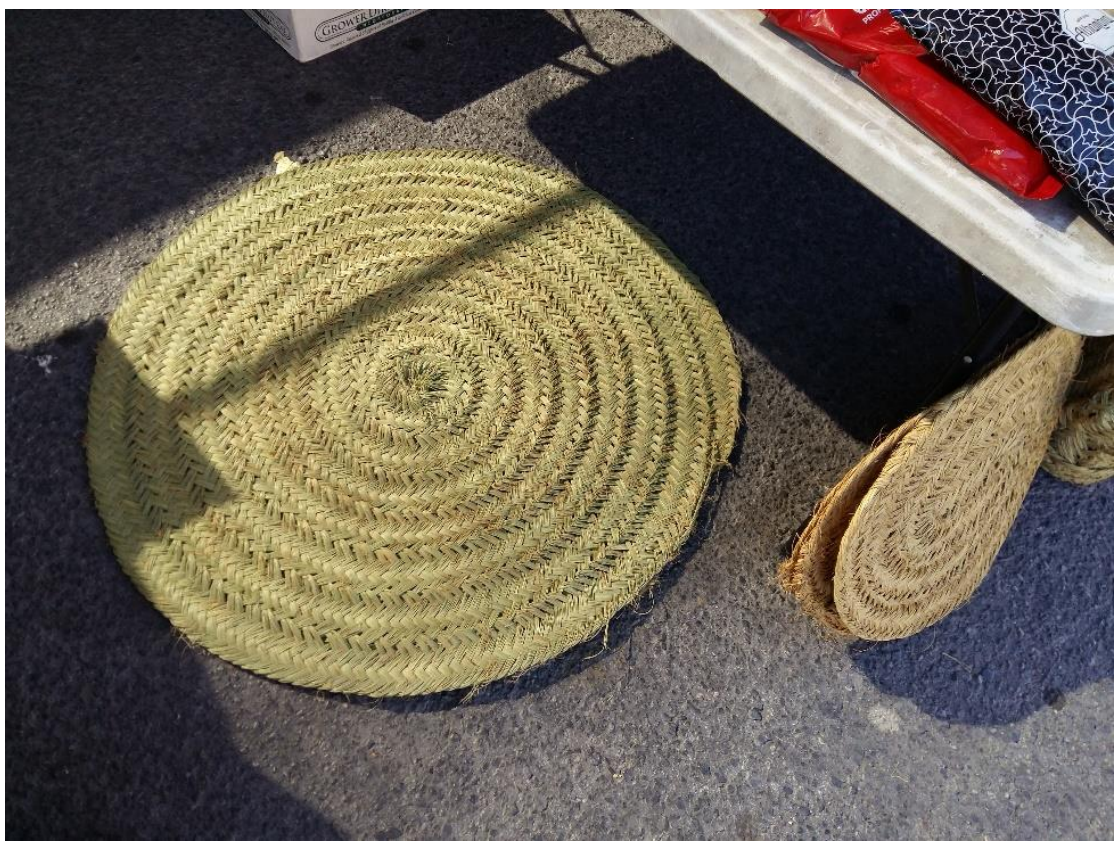

Fuente: Colección personal de la autora, 2020. Mercado ambulante de La Cala del Moral. Málaga.

Figura 6 - Estera, bolso y canastos de esparto y pleita

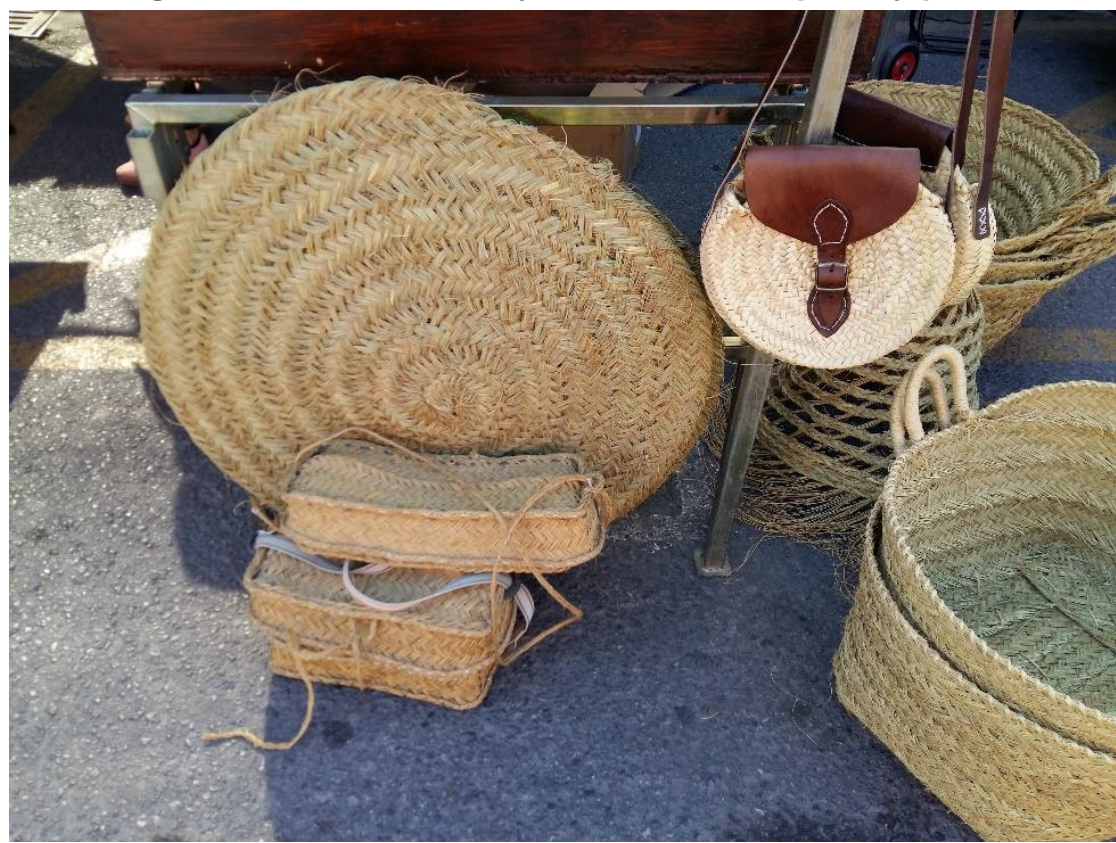

Fuente: Colección personal de la autora, 2020. Mercado ambulante de La Cala del Moral. Málaga.

Una historia de vida en tiempos de la postguerra española.

Revista GEARTE, Porto Alegre, v. 7, n. 3, p. 510-535, set./dez. 2020.

Disponível em: http://seer.ufrgs.br/gearte 


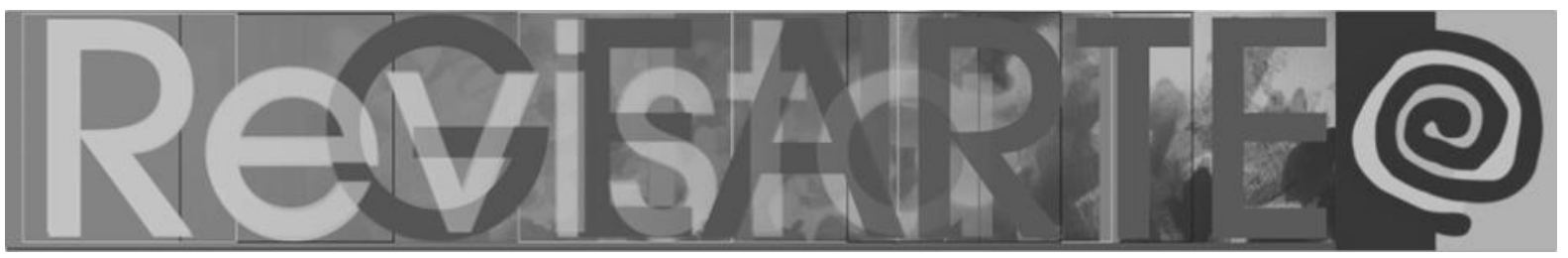

Figura 7 - Cabezas de toro, lámparas, bolsos...

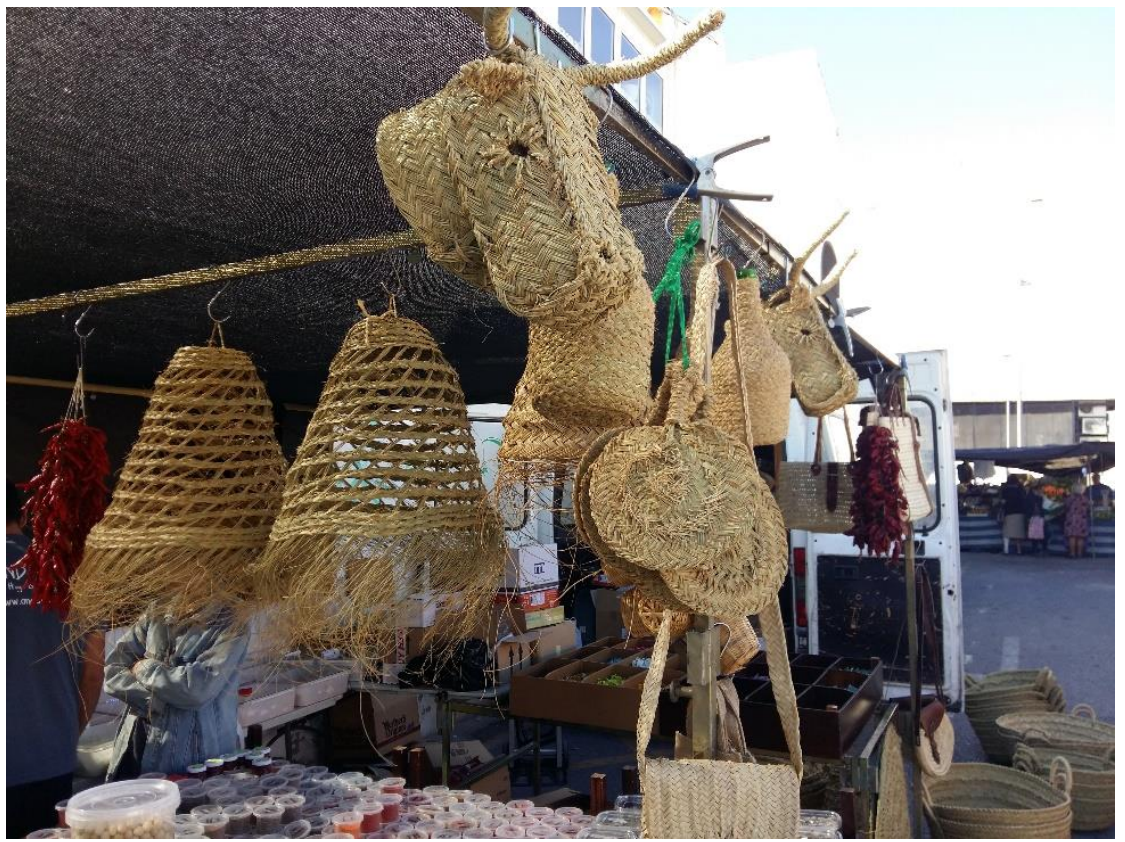

Fuente: Colección personal de la autora, 2020. Mercado ambulante de La Cala del Moral. Málaga.

\subsection{Un poco de historia}

Para conocer algo o alguien, se necesita antes conocer su historia. Nos situamos en una España que quizás contrariamente al final de otros muchos conflictos bélicos de su pasado, se halla totalmente agotada a nivel moral. Sin escorzar procesos políticos ni ideológicos, hay que contemplar que una guerra civil supone siempre daño doble para el país que la sufre, ya que todas las facciones beligerantes están integradas en un mismo pueblo. Del mismo modo se hace imperativo tener en cuenta la implementación de una guerra de terror durante tres largos años, en la que la población civil vivió de continuo persecuciones, internamiento en campos de concentración, ejecuciones en masa en cifras que impelen a buena parte de historiadores a tratar el asunto como un "genocidio", y del quebranto de espíritu que supone para la población estar avasallado por una realidad inundada de violencia en una relación muy asimétrica de fuerzas y de la que no existe forma alguna de escapar. 


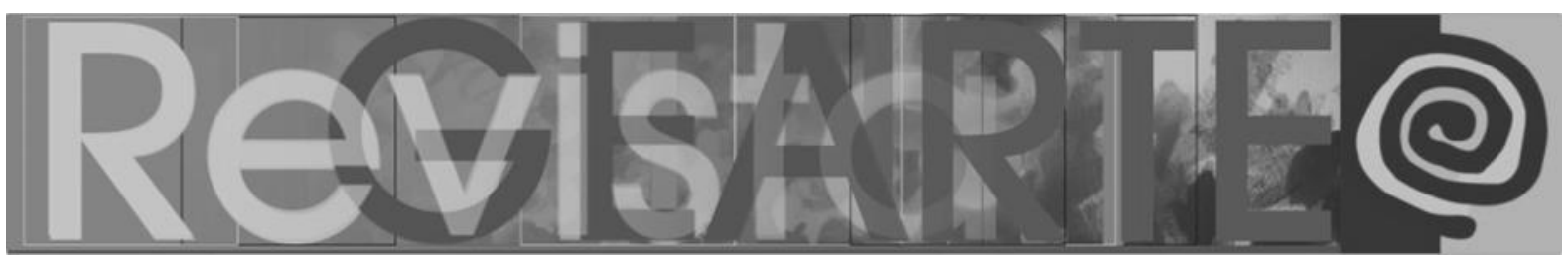

Al contrario que otras naciones europeas (como trataría de relatarlo García Berlanga en su famoso largometraje Bienvenido, Mister Marshall), España jamás recibió ayuda por parte de los Estados Unidos de América ni de la Organización de las Naciones Unidas, como tampoco penetraron las tropas aliadas para liberar el país que había sido el laboratorio de ensayos y pruebas del ejército fascista italiano y nazi alemán y que quedó abandonado a su suerte salvo, irónicamente, por un tímido apoyo proporcionado por Stalin. No sería hasta los tardíos años sesenta, desde finales de los años treinta, el tiempo en el que España empezaría a poder experimentar un tímido desarrollo que asemejara en algo la vida de otros países europeos occidentales; con todo, el estado policial y represor jamás desapareció y la dictadura mantuvo una pervivencia de cuarenta años. (PRESTON, 1978, 2011). Esta España desgarrada, rural y convaleciente es el hogar de la protagonista de nuestro relato.

El tradicionalismo del siglo XIX había puesto una semilla en el sistema político social del régimen de Franco. "Había que repensar España, conocerla mejor, rebuscando en su pasado, en la tradición, en el pueblo, en sus costumbres ancestrales" (CABRERA en PELTA, 2016, p. 1). Ello era imprescindible para poder acceder a su control. Fusi (1999, p.101), expresa que la política cultural franquista fue más una política de control que "una política afirmativa de creación de una cultura propia y original", como debiera haber sido.

Aparecen dos visiones. De una parte, un punto de vista tradicionalista, basado en la idealización del reinado de los Reyes Católicos como período de gran gloria, la estética de Castilla y sus paisajes, el papel en la pintura de El Greco y Velázquez, así como el interés en la cultura grecolatina. De otro lado, aparece un neopopulismo que exalta lo folklórico y se provoca el retorno a una mirada del mundo rural. Surge un renovado interés por la artesanía de este modo, con numerosas manifestaciones. 


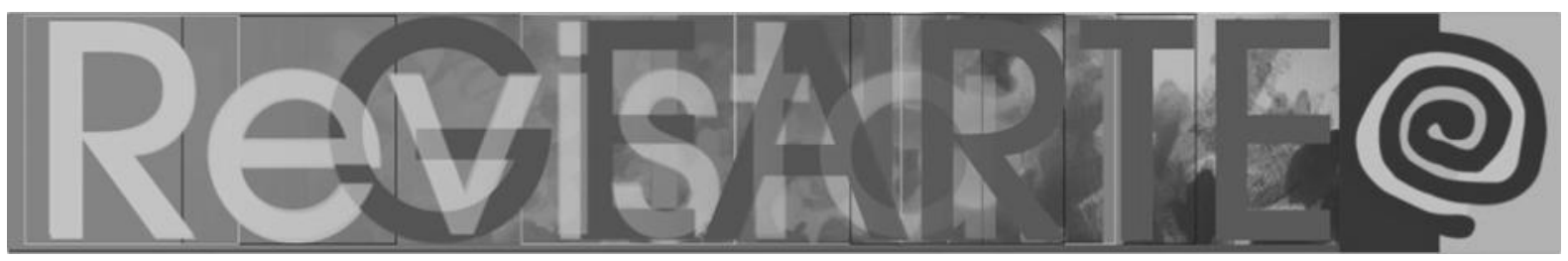

En un país que trata de resurgir de la guerra civil, con unas mermas notables, arruinado y débil, se trata de manifestar la artesanía como una visión anti-ciencia y anti-industria, ya que interesa promocionarla como forma de subsistencia.

Desde el territorio del arte y la estética, se trataba de retornar la artesanía al plano que le correspondía. Se necesitaba poder detenerse en cuestiones como "considerar al arte como revelación, la superioridad del contenido, de la ética, la rehumanización..." (CABRERA, 1998, p.238).

En la sociedad de la postguerra, la artesanía tiene un peso importante debido a varios factores; en primer lugar, eran actividades que rendían cierto beneficio económico garantizando a veces la subsistencia de familias al completo, y por otro lado no exigían el nivel de rendimiento físico que podían conllevar los campos, los rebaños, la albañilería o, en contextos más específicos, la vida en una fábrica. Buena parte de los sectores de la artesanía podían ser llevados a cabo por ancianos, niños o impedidos, figuras que eran muy frecuentes en estos sectores. El esparto no era una excepción a este respecto.

Por otra parte, el sistema de producción doméstico que conllevaba la artesanía no implicaba la optimización de la potencia del ser humano como especie, ni la mecanización del esfuerzo que supone un rendimiento sin pausa. Esto repercutía en que, al contrario del mundo industrial, se podía abarcar un contingente de población enorme como "fuerza de trabajo", ya que las acumulaciones de capital no tenían detrás una inversión que las impulsase de forma tan clara como la fundación de una fábrica, ni existían cálculos para el logro de una manufactura masiva empleando la menor cantidad de operarios posible. Además, la artesanía rara vez exigía el transporte de materias primas desde larga distancia, no demandando así líneas ferroviarias, o en caso de que hubiera materiales escasos a mano, la producción de baja intensidad permitía espaciar los 


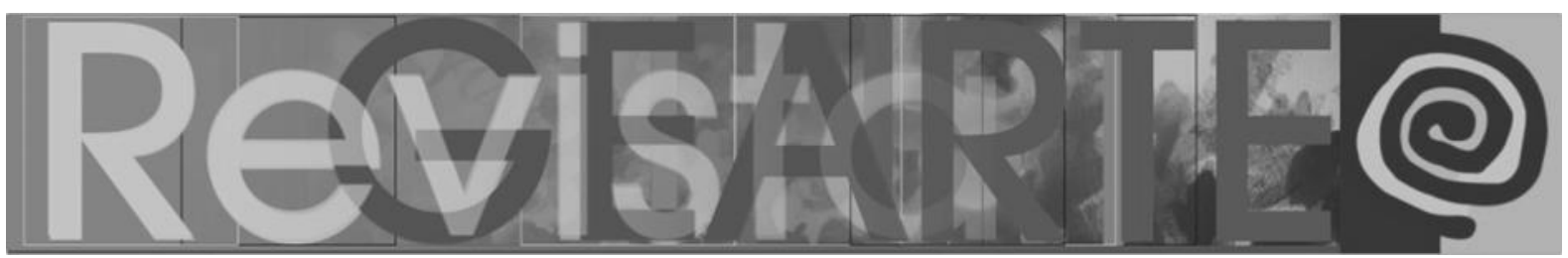

tiempos y emplear unas líneas de transporte tradicionales que no demandaran de

España una red de comunicaciones de un nivel más alto que el medieval.

La relación humana con su entorno más inmediato a lo largo del tiempo ha dado origen a oficios que desde entonces dieron sentido a su vida y ocuparon su quehacer diario. Uno de esos oficios, ahora ya en desuso por la irrupción en el mercado de nuevos materiales y procesos más mecanizados es el del artesano del esparto o también llamado espartero.

\begin{abstract}
Las primeras noticias del esparto llegan desde el mundo romano, reflejado en los textos de Estragón o Plinio desde el año 500 a.C. los romanos comercializaron esta industria, sobre todo en las actuales provincias de Granada, Almería, Murcia y en La Mancha. Adquiere su mayor importancia en zonas como Herencia (Ciudad Real), rodeada de montes o sierras. El trabajo con el esparto formaba parte del salario. Lo realizaban los mayorales y pastores en el campo de quintería por las noches si llovía o simplemente para distraerse quedándose los jornaleros a cargo de la labor. Los trabajadores del campo aprovechaban los días de lluvia y las noches para elaborar los utensilios que necesitaban para el desarrollo de sus ocupaciones. En las grandes casas de labor este trabajo lo realizaban cuadrillas tras la siega del trigo o la cebada para posteriormente venderlo en las casas al peso, en fardos, kilos o arrobas. (DÍAZ-PAVÓN, 2014).
\end{abstract}

Miramos hoy este oficio artesanal, tan preciado por todos como supervivencia y tan valorado hoy en día como patrimonio cultural y artístico español. José Fajardo, profesor de la Universidad Popular y del Aula de Naturaleza de Albacete, en las Jornadas de Esparto de la misma ciudad valenciana expresa que:

Es un poco como el círculo alrededor del fuego, solo que el fuego no está [...] se trabaja en círculo. Es una actividad que es casi una meditación, cada uno está centrado en lo que está haciendo, pero al mismo tiempo y en conversación y es una metodología circular en la que todo el mundo aprende a la vez; cuando alguno tiene una duda le pregunta al que está al lado. Hay gente que está especializada en un tema concreto y es el que van y le preguntan de eso, gente que sabe muy poquito, gente que sabe mucho y todos trabajando a la vez.

Nos estamos pasando un poco con las nuevas tecnologías y eso hay que hacerlo compatible con actividades tradicionales que aportan otras cosas que estamos perdiendo. (FAJARDO, 2019) 


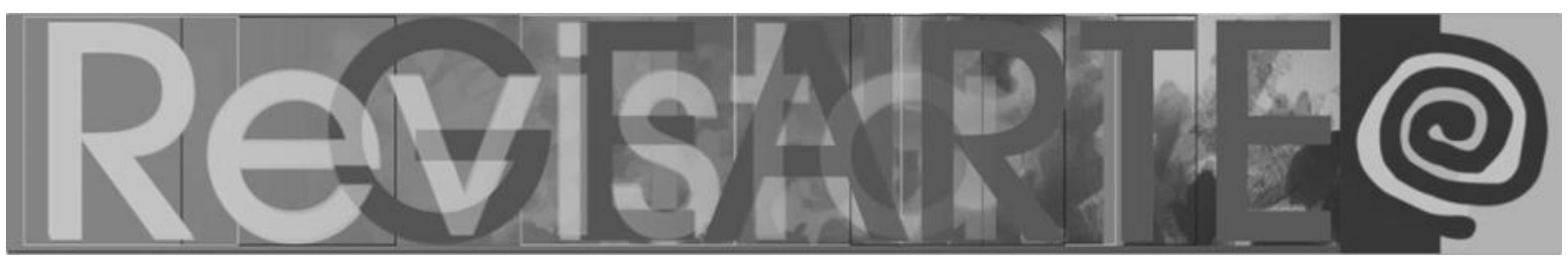

1.3 Las historias de vida como estrategia educativa. Cómo se crea una identidad

La constante búsqueda de nuevas estrategias de innovación educativa nos lleva a las historias de vida como material sensible para transmitir o simplemente presentar aprendizajes vitales de otras personas y observar si tienen relación con nuestra propia vida.

Podemos observar cómo aquellos incidentes que vivimos de forma dolorosa, ya sea física o emocionalmente, marcan parámetros sobre la identidad de cada persona. Berger (2001, p.114) escribe que "en la vida, el momento que descubre todos los momentos pasados y venideros suele ser por lo general un momento de dolor físico". Y al hablar sobre Bacon, manifiesta la búsqueda que pretende en su obra cuando dice: "lo que quiero hacer es distorsionar la cosa hasta tal punto que pierda su apariencia, pero dejando constancia de ésta en esa misma distorsión". Quizás podemos entender que el arte es una forma de escape de la realidad cuando no es asumible y nos lleva a imaginar distorsionando y cambiando lo que existe en algo bello o aceptable.

La reciente neurociencia aplicada a la educación nos muestra la importancia de selección de las actividades para llegar a conformar nuestros cerebros hacia una vertiente humana, empática y sensible hacia las demás personas. Lo habitual es que las personas viven hechos desde la infancia que quedan enterrados en el inconsciente, por no saber cómo manejarlos en esas edades. Ello forma parte de la construcción de nuestra personalidad, de nuestra actitud ante la vida, así como la creación del proyecto vital singular, siendo este el último fin de la educación. Con ello también forjamos nuestra identidad. Según Kahnemamm (2012), si pensamos que tenemos razones para creer en lo que creemos, usualmente estamos equivocados. Nuestras convicciones, nuestros deseos y nuestras esperanzas no están siempre anclados en la razón. Y añadiría que gran parte de los cimientos de nuestra propia identidad se apoyan en vivencias dolorosas y en respuestas halladas a tales momentos. Básicamente podemos ver la creación de nuestra 


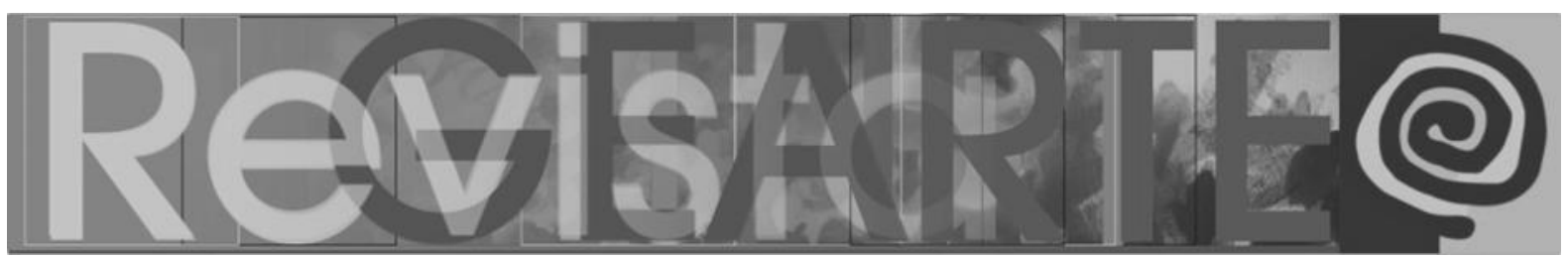

identidad como una obra artística, donde la frustración (no siendo la única vía) hace de trampolín para crear salidas y experimentar un pensamiento divergente creativo.

Como destaca Pérez Gómez (2012, p. 212-213), "La motivación educativa, la motivación intrínseca, ha de vincularse a la autodeterminación, a la capacidad de elegir y desarrollar el propio proyecto vital, lo que requiere libertad y responsabilidad, autonomía y esfuerzo".

Para Csíkszentmihályi (1990, p. 312), es esencial el alcanzar la personalidad autotélica, considerando que "transforma experiencias potencialmente entrópicas en flujo". De este modo,

\begin{abstract}
Las fuerzas exteriores no determinan si la adversidad será capaz de convertirse en disfrute [...] La diferencia entre alguien que disfruta de la vida y alguien que está abrumado por ella, es producto de la combinación entre los factores externos y la manera en que la persona los interpreta, es decir, si ve los desafíos como amenazas o como oportunidades para la acción. (CSÍKSZENTMIHÁLYI, 1990, p. 311)
\end{abstract}

Cuando no se consigue este estado de flujo, habitualmente las personas ponen la responsabilidad en las circunstancias externas y en las otras personas viéndolos como causantes de sus desgracias. Este es el recuerdo que puede quedar a las personas cuando ocurren incidentes de dificultad en su niñez que no pueden solventar.

Las historias de vida suponen un punto de vista crítico y reflexivo sobre la persona de la que se habla, al tiempo que ponen un punto de vista en dos tiempos diferentes, pasado y presente para cotejarlos y valorarlos. No podemos olvidar que esta forma de pensamiento será base para el desarrollo de la creatividad.

En el trascurso de la historia que se cuenta, los aprendices aprenden a mirar a la persona en cuestión y conocen el sentimiento de la empatía por descubrimiento propio. Ocurre la identificación o la diferenciación con el personaje que observan al tiempo que se logran interpretaciones personales sobre los 


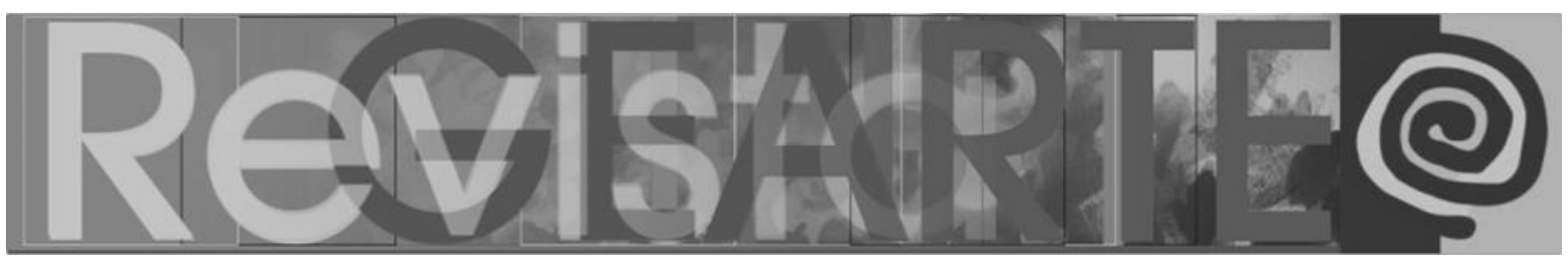

hechos que se narran. El análisis de otras vidas lleva al alumnado al desarrollo de valores personales, de emociones, comprensión de las situaciones, propósitos y actitudes ante sí mismos y ante los demás seres humanos.

Teniendo en cuenta que estamos hablando de una historia en la que se entrelaza la artesanía con la vida misma, siendo esta la forma de supervivencia, contemplamos que toda forma de arte deja huellas profundas en la vida ya que en sí mismo desarrolla capacidades, habilidades y destrezas, actitudes, emociones y valores de la persona. El arte propicia la parada en el tiempo en cualesquiera circunstancias y la aparición de una mirada interior hacia lo más profundo de uno mismo. Buscamos entrar en ese diálogo interior que genera la reflexión de las vivencias propias, donde una empieza a descubrirse y conocerse y a partir del cual se construye la verdadera identidad por autoanálisis.

\section{Objetivos}

2.1 Relacionar la artesanía con las historias de vida como estrategia educativa.

2.2 Indagar en los factores que conforman la identidad de Electra.

\section{Método}

\subsection{Una investigación cualitativa: La historia de vida de Electra.}

Con este trabajo tratamos de capturar el sentido que encuentra Electra a su vida, de forma subjetiva, al pasar los años y, al mismo tiempo, canalizar la manera en que percibe el significado de su vida social en el contexto determinado de la posguerra civil española. A través de su propia mirada pretendemos comprenderla como persona. Sus vivencias a los once años de edad marcarán el sentido que ella da a su vida posteriormente.

Las personas se guían en muchos momentos de su vida por sus creencias, y valores, por ello conocer como una persona cree que han cambiado las cosas y saber qué es lo que considera ha determinado su 


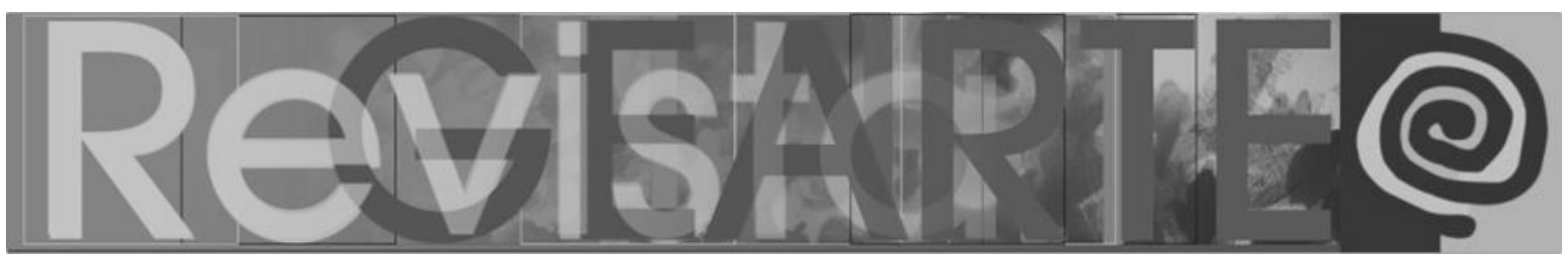

vida, puede ayudarnos a comprender a esa persona en particular (VILLAR, F.; TRIADÓ, C., 2006 en: IDIAQUEZ, M. et al. 2015, p.6).

Un aspecto, a resaltar en las historias de vida, es que tienen un carácter cambiante. Con el paso del tiempo y las nuevas vivencias de la persona, así como su madurez, los acontecimientos suelen verse desde un prisma diferente. Electra mira hacia atrás en el tiempo y ve cómo ante su abnegación obligada y su resistencia interior al mismo tiempo postula una forma de vida que marcará su proyecto vital en el futuro. Desde aquí en el año 2020, Electra se mira a sí misma como niña, comprendiéndose y comprendiendo su situación y a su familia, las emociones y decisiones de sus padres que tiempo atrás no entendió.

Las historias de vida son historias inacabadas, se relatan en un determinado momento de la vida, pero la vida sigue, y la historia se sigue construyendo. Cada nueva vivencia puede no solo añadirse a la historia de vida, sino que puede cambiar la manera de ver y entender acontecimientos pasados (VILLAR, F.; TRIADÓ, C., 2006 en IDIAQUEZ, M. et al. 2015, p.6).

Planteamos esta investigación, basándonos en la narrativa de las historias de vida. Nos posicionamos en la etapa de los once años de la vida de Electra, tomando como marco sociocultural el año 1947 de la posguerra española y la artesanía del esparto como medio de supervivencia familiar.

Llevamos a cabo una investigación de corte cualitativo, tomándola como un proceso vivo. Stake (2010, p. 29) dice que "en un proyecto de investigación cualitativa, los temas aparecen, crecen y mueren". Debemos considerar que a lo largo del camino pueden aparecer elementos que por azar nos conduzcan a unos derroteros no contemplados al comienzo, temas emergentes. El propio material recopilado puede tomar distintas direcciones o puntos de vista al presentarlo.

En esta narrativa contemplamos al lector como parte integrante del proceso. Seguimos a Dilthey cuando expone que "tratamos de facilitar la comprensión al lector, ayudar a comprender que las acciones humanas importantes pocas veces 


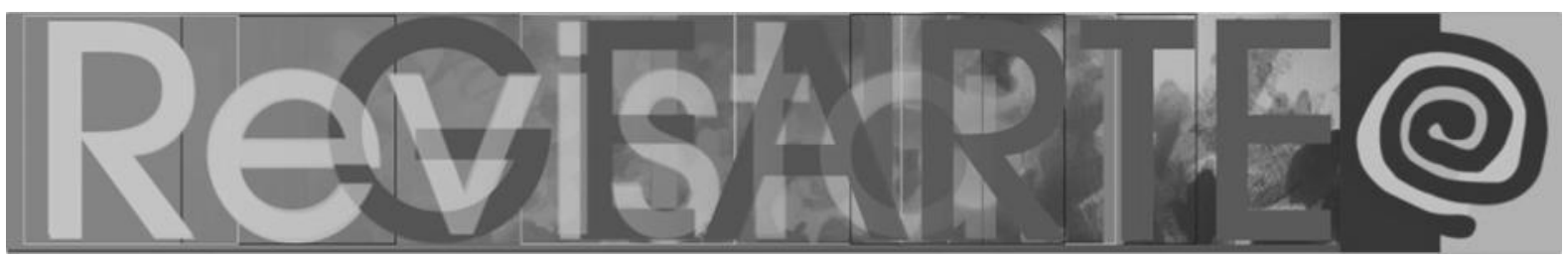

tienen una causa simple y que normalmente no se producen por motivos que se pueden averiguar" (STAKE, 2010, p. 43).

Buscamos pues empatizar con Electra para poder comprender sus vivencias. Su realidad es compleja. Intervienen muchos factores tanto intrínsecos como externos. Mediante la descripción tratamos de transmitir al lector, al alumnado en su caso, la propia experiencia que se escribe.

\subsection{El camino}

Hemos recorrido diferentes etapas:

El comienzo del camino andado se da en el mismo instante de plantear a Electra este trabajo. He de decir que hemos mantenido este nombre, su primer nombre, por deseo y decisión de ella misma. A pesar de que han pasado setenta y siete años con un nombre nuevo, ella sigue sintiendo afinidad por aquel primer nombre que la transporta a su infancia.

Acordamos hablar sobre su vivencia en aquel 1947, de cómo ella trabajaba el esparto como ejercicio impuesto por su padre para poder obtener dinero para la supervivencia básica familiar. Electra ha escrito de su puño y letra varias páginas de un cuaderno donde ha comenzado a contar su vida. A sus ochenta y siete años quiere dejar registro y recuerdo de sus vivencias y me pide que, aunque a mí me lo cuente todo, solo escriba aquello que ella permita. Ante todo, Electra muestra cariño y respeto por sus padres que ya no viven y quiere mantener su memoria como personas que lucharon inmensamente para poder superar una guerra, con campo de concentración para su padre y lucha de soledades y pobreza de su madre para mantener a sus hijos. La admiración a ellos y el amor que les guarda lleva a la comprensión de la dureza de su vivencia familiar, dedicada por encima de todo a subsistir.

Es necesario decir que este trabajo comienza a forjarse en un periodo en el que aparece un confinamiento mundial debido a la llamada Pandemia por COVID- 


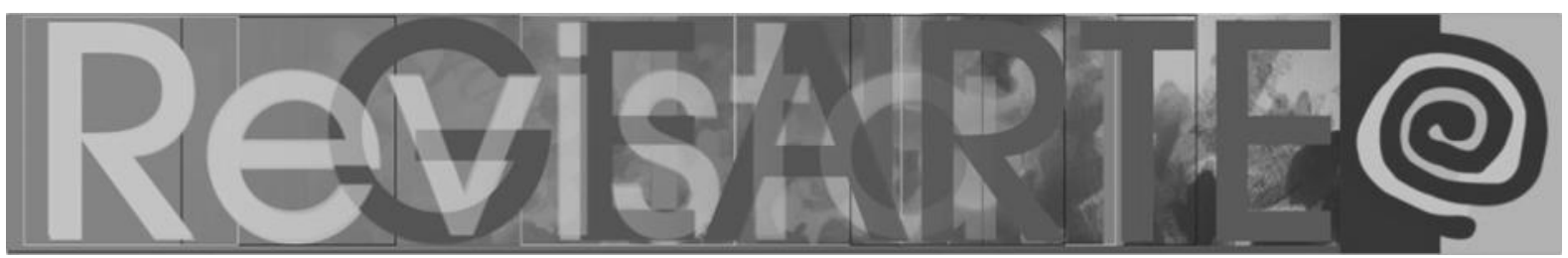

19. Por tanto, las primeras ideas sobre la forma de llevar a cabo esta investigación han tenido que ser cambiadas. En principio se pensó en hacer unas entrevistas a Electra, así como llevarla a visitar los pueblos de Alameda y Alhaurín el Grande donde situarse en las mismas calles y casas donde vivió y poder hacer algunas fotografías que documentaran este trabajo. Del mismo modo, la visita a un taller de esparto donde algunos maestros esparteros siguen esta tradición artesana. El confinamiento ha hecho imposibles estas actividades, por lo que me he visto impelida a cambiar el rumbo de actuación. Para proporcionar un ambiente cercano, se ha mantenido el contacto con Electra asiduamente hablando sobre cosas cotidianas, sensaciones y miedos ante esta enfermedad.

Posteriormente, una vez pasamos en Andalucía a la fase 1 del desconfinamiento, visité a Electra a su casa, donde me ofreció sus relatos escritos y hablados que se grabaron para ofrecer citas aquí en este trabajo.

El trabajo de entrevistar a un espartero quedó relegado a los videos que la comunidad cultural expone en internet. Sin embargo, podemos aportar algunas fotografías hechas en la colección que vende un artesano en el mercado de Málaga. Todo ello se ha cotejado y confirmado con las exposiciones de Electra.

\section{Resultados. La historia de Electra y el esparto}

Electra es una niña nacida en Alameda, un pueblo de la localidad de Málaga, al sur de España. Su nombre es elegido por uno de sus tíos, estudioso y artesano, referido a una de las siete estrellas que forman la nebulosa de las Pléyades en la mitología griega. No obstante, tras la guerra civil y ante el miedo que todavía queda en las gentes, esta niña será despojada de su nombre, su identidad y bautizada con un nuevo nombre cristiano.

Como pueblo eminentemente agrícola, los hombres y las mujeres de Alameda trabajan en las labores tradicionales del cultivo y recolección de la aceituna y del trigo. En el tiempo en que esto no es posible, se dedican a la 


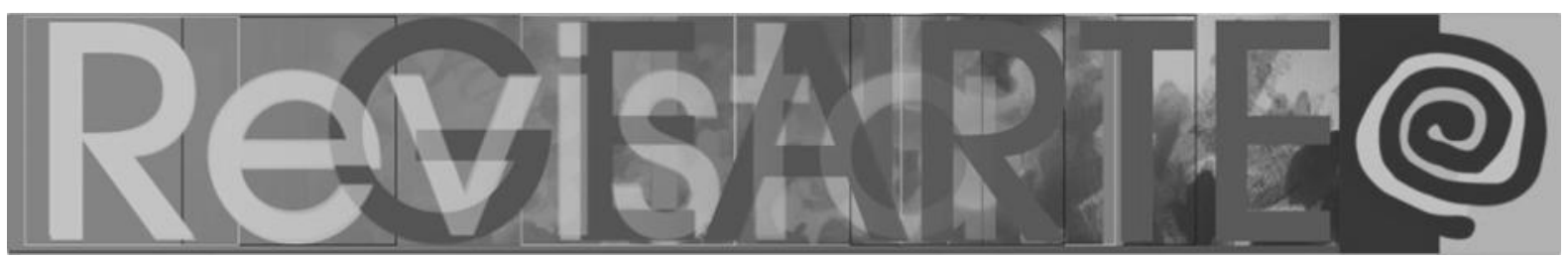

recogida del esparto en la sierra y la palma o pita en la ribera del río, como materias primas para elaborar de forma artesana los materiales necesarios para el uso en la vida cotidiana.

Corre el año 1947. La familia de Electra ha llegado hasta Alhaurín pidiendo trabajo y techo para ellos y los siete hijos que han sobrevivido. El dueño de un molino les ha dejado vivir dentro -ahora está vacío porque no es tiempo de aceitunas para molienda-, hasta que puedan ganar un poco de dinero para arrendar una casa donde vivan mejor. Los padres de Electra han vivido hasta hoy del trabajo del campo, la recogida de aceituna y del esparto. Son también naturales de Alameda, donde aprendieron la artesanía de este elemento desde muy jóvenes para trabajarlo y venderlo. Ella cuenta así:

\begin{abstract}
Mi padre me enseñó a mí, me acuerdo. Mi padre sabía hacerlo y también mi madre. Mi madre había trabajado en un taller de esos de joven. Había un hombre, por ejemplo, que le decían el manijero que era encargado, a lo mejor de diez mujeres o veinte y las llevaba a un cortijo y las ponía a trabajar a todas y luego les pagaba y él se las entendía con el amo. El amo le suministraba el esparto y ellas estaban trabajando allí, en un taller. Todo el día trabajando, las pobres. Y decía mi madre que de noche iban a una alberca a bañarse porque no tenían otro apaño en el cortijo. Había muchos talleres así de mujeres en Alameda. Y ahí trabajó mi madre mucho antes de casarse, porque allí nada más que había el trabajo de la aceituna o el esparto. Cuando no había campo era el esparto. (ELECTRA, entrevista de 14 mar 2020).
\end{abstract}

Tras la guerra, las familias trataron de retornar a sus pueblos algunas veces andando y otras en carros, o paraban en el camino en algún pueblo para alimentarse y buscar la forma de vivir. Alhaurín (en la actualidad llamado Alhaurín el Grande). se presenta como un pueblo con una tierra más rica. "Allí podíamos comer frutas de los árboles y nadie nos decía nada", refiere Electra, "era poder comer cosas buenas, después de no haber tenido más que acelgas y patatas". "Allí el molinero le dio trabajo a mi padre para hacer las capachas que le hacían falta para el molino de aceite y estuvimos un año entero" (ELECTRA, entrevista de 14 mar 2020). 


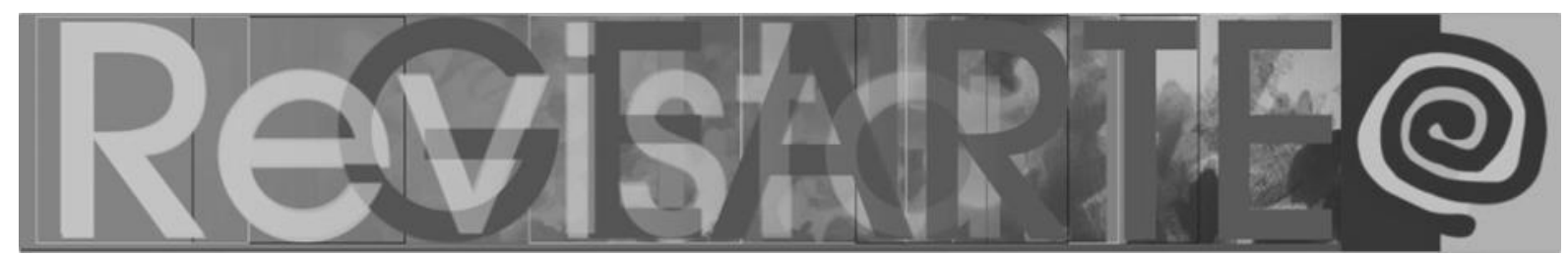

Nos poníamos la Isidora, el Juan y yo. Yo tenía once años. Hice ocho docenas de esteras de 80 (centímetros de diámetro). A mi hermana la ponían a hacer los capachos que tenían un borde así para arriba con unas vueltas más haciendo borde. Ahí se echaban las aceitunas molidas y luego lo otro era como una tapadera que eran las capachas y encima le ponían la prensa y salían unos chorros de aceite y alpechín. Luego eso lo separaban porque el aceite se viene arriba.

Nos sentábamos en una silla y poníamos al lado como un cajón de madera; porque eso, vas haciéndolo, dando vueltas y va creciendo, creciendo y luego se tiene que sujetar en algo para que tú lo puedas llevar. Vas haciendo con tres ramales como una cuerda, pero que va pegada una a otra en círculo, hasta que llegas a 80 o 90, lo que sea. Necesitabas un cajón al lado y estabas sentada en una silla. Y así pasábamos el día. Todos los días hacía tres. Yo que era una niña con once años y hacía todos los días tres capachetas... y mi padre decía: "hasta que no termines no te acuestas". Y se quedaba allí con nosotros y lo teníamos que hacer [...] Yo lloraba porque no quería estar sentada ni hacerlo porque me pinchaba y eso se metía por las uñas y no veas lo que dolía (ELECTRA, entrevista de 14 mar 2020).

Relacionamos la vivencia de Electra - como cualquier niña que comienza a pensar qué quiere hacer-, con los entresijos de su pensamiento, sus deseos, su incertidumbre y la sumisión ante el trabajo que le pide la vida cuando ella se evade y sueña con poder hallar en los libros otras historias, otras vidas y otros mundos. Mientras trabaja el esparto su imaginación crece. Electra cuenta que cuando iba a la escuela muy pequeña, la maestra solo les enseñaba a contar hasta veinte a los más pequeños y tenían que quedarse sentados todo el tiempo que los mayores estudiaban. Ella no quería ir a la escuela porque le resultaba aburrido estar esperando "nada". Sin embargo, cuando tiene que estar sentada haciendo esparto, su mente vuela a aquellos días en que no tenía que cumplir aquel trabajo, sus tres esteras diarias. Y es entonces cuando su mente sueña y se imagina en una escuela y ella postula aprender, cosa que nunca ha dejado de hacer hoy por hoy. Según Dickinson (1960, pp. 688-689), "la lenta mecha de lo posible es encendida / por la Imaginación". "Ella, (como Dewey, Stevens y Arendt) también sabía que el simple hecho de que imaginemos que las cosas sean de otro modo puede ser el primer paso para que actuemos guiados por la creencia de que pueden cambiarse" (GREENE, 2005, p. 42). Para Dewey (1934, p.272), la imaginación es la "puerta de entrada" a través de la que los significados derivados de experiencias pasadas llegan hasta el presente [...] es el ajuste consciente entre lo nuevo y lo viejo". 


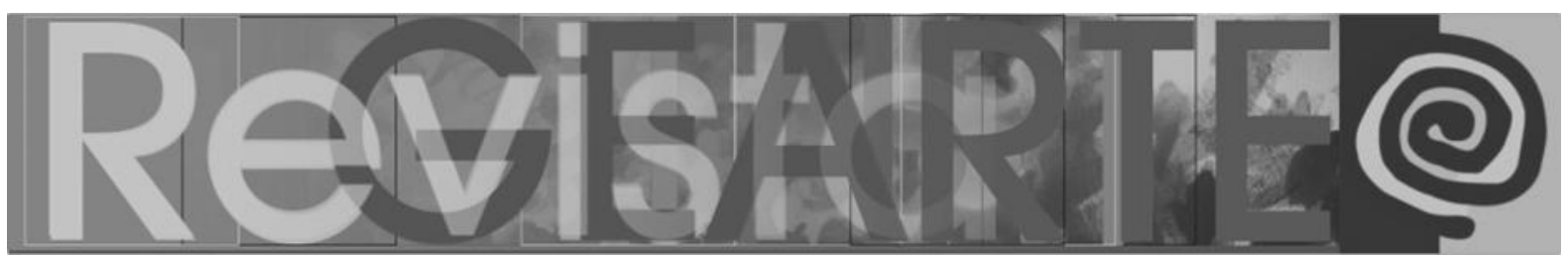

No le hicieron falta las escuelas, pero los libros siguen siendo sus más fieles compañeros. Es aquí con estas vivencias donde se forjan algunas decisiones de su vida, como estudiar y ser una habilidosa artesana en materias delicadas, como la costura de ropas, el crochet, tejer prendas de punto o la cocina. Encontramos la valoración de la artesanía en su vida posterior como positiva, como algo que le ofreció aprender una disciplina, aceptar unas reglas y acabar lo que se empieza, para llevarla a contemplar y juzgar si era eso lo que quería en su vida y tener el impulso de superación como persona. En su juicio crítico, encontrará un camino de reafirmación en el estudio y también guardará siempre el apego a la artesanía, que luego manifestará y transmitirá a sus hijas. La artesanía manual delicada será siempre para ella una utilidad y un placer con el que desmenuza el tiempo mientras pasan labores por sus manos. Hemos de decir que Electra tiene cinco hijas de las cuales cuatro son maestras y una asistente técnica sanitaria y todas son artesanas o artistas en algún ámbito.

Cuando se le pregunta a Electra cómo pasaba sus días además de hacer esteras, aparece su sonrisa y relata cómo distendía el trabajo con su hermano cuando sus padres tenían que alejarse para ir a comprar o estaban trabajando en otro lugar:

Mi hermano Juan tiene dos años más que yo. Los otros eran más pequeños. Cuando mi padre no estaba o mi madre, nos poníamos a jugar. Decíamos: Vamos a hacer una choza fuera. Con matas de olivo o lo que fuera hacíamos una choza y nos metíamos dentro, decíamos para estar más fresquitos. Estábamos por lo menos fuera de la casa. (ELECTRA, entrevista de 14 mar 2020)

Observamos cómo aparece la imaginación y la creatividad de forma natural. Al mismo tiempo podemos ver cómo a pesar de su corta edad y el deseo de juegos, ambos, Juan y Electra, presentan obediencia a sus padres y hacen su trabajo dándole una perspectiva diferente, alterando la realidad a su antojo y beneficio. En todas las historias de Electra está su hermano Juan. Él, a sus noventa años, expresa desde su recuerdo, que había poco tiempo para juegos: 


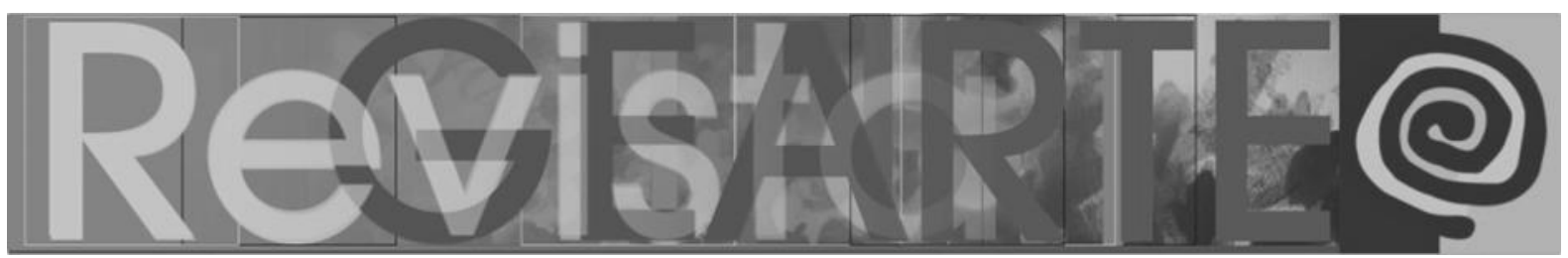

Lo vivíamos pensando en la tarea que teníamos que hacer y en el sufrimiento que pasábamos haciéndolo también. El esparto en la sierra de Alhaurín el Grande, he subido más de una vez a por esparto. También lo cogía de la sierra, que costaba mucho trabajo y tenías que buscarlo y no solo en la sierra sino en el llano de Coín que ahí se cría mucho esparto también. Pasamos por la sierra de Antequera, que hay unos caminos por ahí por la sierra y van allí a los llanos esos de Coín, que tiene muchas huertas y luego ya pasamos a Alhaurín el Grande. Mi padre se colocó en el ferrocarril, ese de vía estrecha que iba de Málaga hasta Coín. Hubo unos inviernos malos y la tierra de la sierra se corría y tapaba la vía. Y había que quitarlo a palas para que pasara el tren. Cuando no tenía trabajo en el ferrocarril también iba por esparto. Íbamos a la sierra. Me ha tocado ir solo y también iba con él otras veces. Teníamos que madrugar desde Alhaurín que vivíamos en una casilla del campo y madrugábamos e íbamos hasta El Chorro, en lo alto del pueblo. Allí había uno que era capachero e íbamos a hacer capacho allí. Él lo vendía y nosotros trabajábamos para él. Los vendía para sacar el aceite a los molinos. Otros días teníamos otros trabajos que no eran tan duros como trabajar el esparto. Jugar, jugar, pocos juegos. (JUAN, entrevista de 13 jun 2020)

Sin embargo, Electra refiere la vivencia que ha quedado en su recuerdo de forma diferente. Él no recuerda ya muchos juegos, pero ella los mantiene vivos:

Otras veces nos íbamos por ahí a pillar un lagarto, que estaba metido en un tronco de un árbol. Y mi padre usaba para coser los capachos unas agujas así de grandes de acero (señala unos 25 centímetros), para que no se abrieran y estuvieran más sujetos, con unas cuerdas también hechas de esparto, sogas de tres ramales que hacía él. Mi Juanillo cogía la aguja de acero y decía: Vamos a pillar un lagarto. Y los lagartos se escondían en los huecos de los perales. Un día mató uno y luego lo desolló y lo frio, porque decía que eso era un aceite muy bueno para untárselo en el cuerpo en las heridas y mi madre hasta tiró la sartén. Otra vez pillamos una serpiente por lo menos de un metro y medio. Yo iba con él, pero el que la apedreaba era él y luego la pusimos en el camino para asustar a la gente ya muerta. Fíjate en lo que nos entreteníamos. (ELECTRA, entrevista de 14 mar 2020)

De cualquier modo, la forma de vida de esta niña, como de su familia en la sociedad del tiempo en que se desarrolla, resulta ser para ella opresiva. La artesanía, como hemos dicho, es la forma de sobrevivir, de obtener algún dinero o intercambio para subsistir cada día, pero no es algo agradable o deseado por entonces.

Paulo Freire (1970, p.78) pensaba que aquellas personas que viven bajo algún tipo de opresión sienten confuso o indiferenciado el material de vida, por lo que probablemente van a tener en algún momento un despertar de la conciencia 


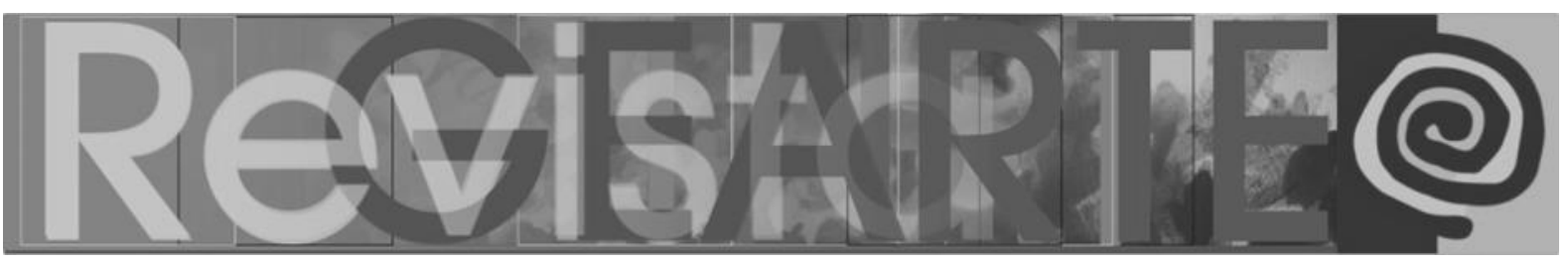

de cómo se construye lo real y se las debe retar a que "nombren" sus mundos vividos y a que transformen esos mundos. Al mismo tiempo, habla de la desesperanza como "una forma de silencio, de negación y de huida del mundo" (FREIRE, 1970, p.80). Para Maxine Greene (2005, p. 46), "las personas que tratan de ser más plenamente humanas [...] deben ser capaces de imaginar algo que resulte de sus esperanzas: su búsqueda debe vencer su silencio." $Y$ así es como Electra pone la mirada en otro tipo de trabajo y en el deseo de crear para sí misma otra forma de vida como luego hará.

Electra no pudo estudiar, pero aprendió sola a leer primero y luego a escribir y nunca dejó de leer libros que le fueron dando un legado cultural. Mas tarde, vivió las carreras y otros estudios de sus cinco hijas, escuchando lecciones y preparaciones de exámenes, donde ella también aprendía.

\section{Conclusiones. Lo que se desvela}

La artesanía del esparto finalmente se presenta ante Electra como un trabajo necesario que rechaza por su corta edad. Ella comprende que no es la artesanía en sí, sino las dificultades que plantea este elemento las que la llevan a no querer trabajarlo; hablamos de la dureza y las heridas que provoca cuando se pincha en los deditos o entre las uñas, así como las infinitas horas que debe pasar sentada en una silla a sus once años.

Podemos observar que, al mirar de frente su vida, Electra, al contarnos su historia, mira mientras habla, a un ir y venir de tiempos pasado y presente, analizando y reflexionando, mirando desde una nueva perspectiva aquellos momentos y llegando a comprender a aquella niña que ella fue, así como las actuaciones de sus padres y la sociedad en la que sobrevivió. Asume un punto de vista diferente al que tiene en su recuerdo. Ahora se plantea más que su propia vivencia, la toma del punto de vista de su madre y su padre, el cómo debieron sentirse después de una guerra volviendo a su pueblo andando y hallándose sin sustento y con la pérdida de una hija pequeña que muere con seis años. Aparece 


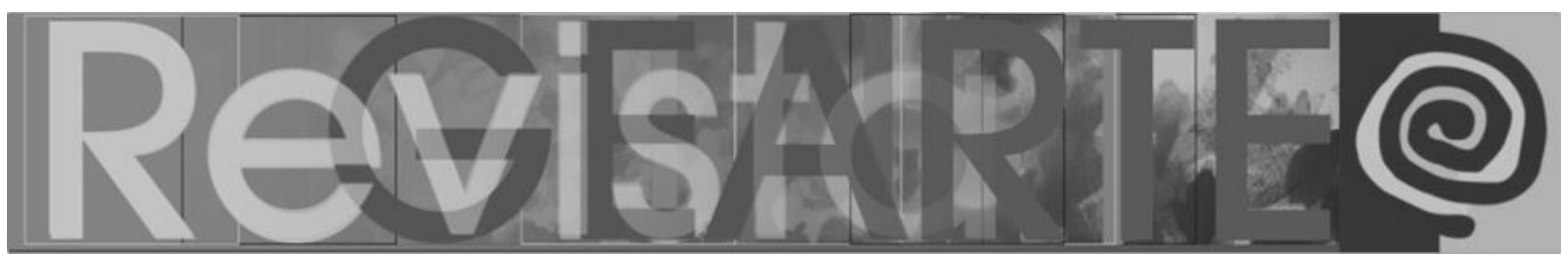

la empatía y el respeto por ellos y el agradecimiento por lo vivido como pudieron. Comprende la dureza de su madre y las exigencias de su padre debido al dolor callado, las dificultades extremas y la impotencia para hallar formas de sobrevivir. Su propia vida toma otro sentido y piensa que realmente ha sido una superviviente, de la guerra y la posguerra y en su capacidad para adaptarse a los trabajos que luego ha tenido.

Al mirar con retrospectiva, muestra agrado de poder conocer y explicar cómo se hace la pleita o las capachas y el placer de saber sobre esta artesanía y su valor de utilidad. Electra comprende desde el presente su pasado y reflexiona sobre él. Comprende que el manejo del esparto era bastante difícil, pero admira cómo su hermana hacía cestas y otros objetos decorativos, desarrollando habilidades creativas y que ella misma siendo más pequeña solo pensaba en no estar sentada.

Hoy en día en España existen numerosos talleres de artesanos del esparto y la pleita. Numerosas personas han compartido y comparten este arte de crear no solo esteras, cestería de pleita o esparto, alforjas y otros, sino diversos objetos de adornos por el placer de su creación. Vemos cómo un elemento tan hostil desde que se busca en la sierra hasta que se teje puede ser un medio de creación artística y despertar el poder creativo, así como continúa siendo medio de supervivencia para algunas personas. (Figuras 1, 2,3,4,5,6 y 7).

De otro lado, podemos hablar del aprendizaje que provoca el trabajar con las historias de vida. No solo es el conocimiento sobre una vivencia, las costumbres o las tradiciones de un lugar en un momento histórico. También es el acercamiento a la persona desconocida de la que se habla, el encuentro de alguien diferente a uno mismo, así como querer despertar sensibilidad y emociones en la persona lectora. Buscamos provocar en el lector una cierta empatía, para reconocer valores y sentimientos propios proyectados en los demás, así como la simpatía y compasión por otras personas. 


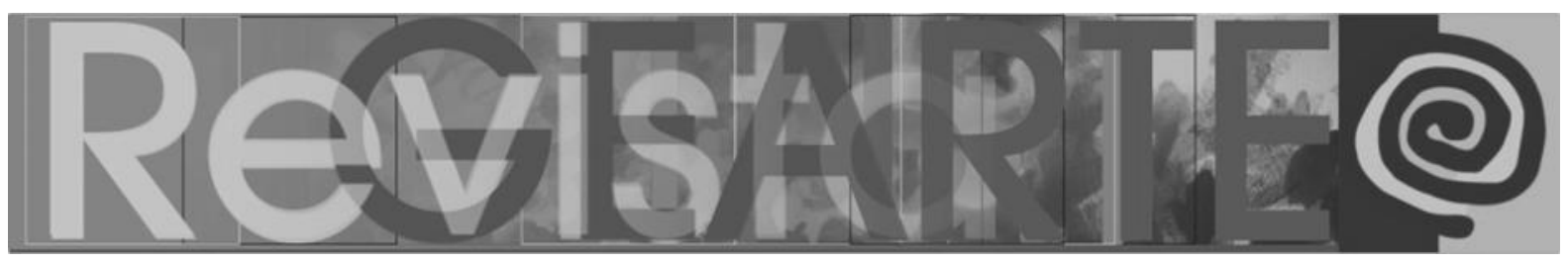

Buscamos una mirada hacia lo más profundo de cada individuo, así como de los estudiantes, para desarrollar la reflexión personal. Por ello incorporamos un diálogo interior y el proceso de metacognición. Este "supone conocerse a sí mismo, quererse y autorregularse" (PÉREZ GÓMEZ, 2017, p.59). Esta mujer ha llegado a saber valorar el esfuerzo y el arduo camino que ha llevado en su vida y mirar con orgullo donde hoy se posiciona. Hablamos también del despertar de una conciencia que traspasa la realidad, que va más allá de lo que la vida ofrece y provoca un cambio personal a voluntad. Electra ha tomado conciencia de que los acontecimientos de la vida han marcado la forma de crear unas direcciones e intenciones, de tomar decisiones y proyectar su propósito de vida. "La conciencia de una persona es la vía mediante la cual se abre camino al mundo [...] ha de ser concebida como una forma de extenderse hacia fuera, como un algo intencionado, como una comprensión de la apariencia de las cosas" (GREENE, 2005, p. 47).

Las entrevistas con Electra han provocado un acercamiento entre la entrevistadora y ella, una mujer con la que he hallado afinidades comunes además del placer de descubrir a la persona que realmente es. Ambas influimos en la vida de la otra. Se trata de una apertura, para conocerse y darse a conocer. El hecho de realizar este trabajo, de alguna manera me ha llevado a la introspección sobre mí misma, a mirarme desde otro prisma, a buscar analogías y diferencias de una forma compleja.

Finalmente, he de desvelar que Electra es mi madre, una mujer a la que siempre he admirado y que ha sido modelo para mí en muchas cosas de la vida. Elaborar este trabajo me ha llevado a la necesidad de establecer una distancia y una observación desde un punto de vista nuevo. Ya no es la madre, es la mujer y la niña. Ha sido necesario en primer lugar ese distanciamiento que permite la objetividad, para poder acompañarla en su proceso de descubrimiento. Pero siempre se establece un diálogo empático entre la persona entrevistadora y la entrevistada. He tratado de mirar su historia y su vida como mujer y comprender cómo ella ha creado su propia identidad en función de sus vivencias, cómo ha ido 


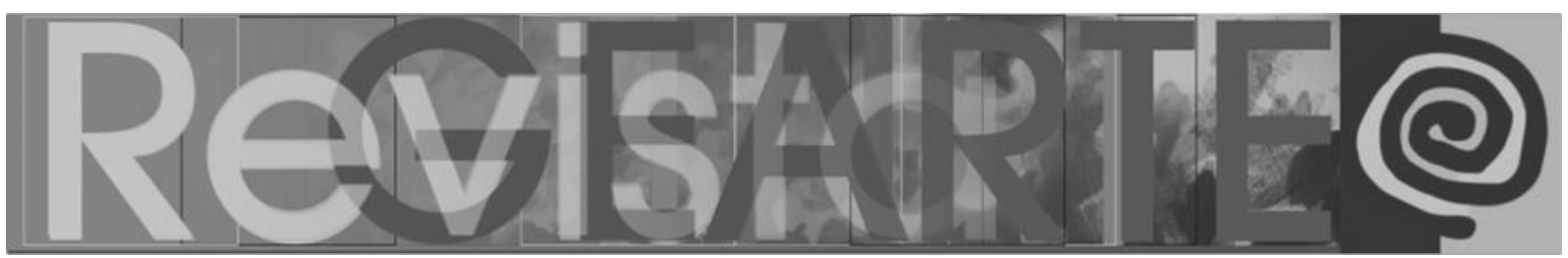

construyendo su vida hasta hoy. Ella ha sido ejemplo para las vidas de sus hijas y de otras personas que han pasado por su vida, al igual que todas las personas influimos en las vidas de los demás desde lo afectivo y la experiencia. Cada uno o una de nosotros conocemos a la persona como madre, pero no como persona.

Este trabajo trata de una mirada hacia la madre, hacia la mujer con el fin de comprenderla y situarla en un plano diferente del habitual. Metodológicamente nos lleva a una pedagogía de los afectos que vincula a las personas y provoca respeto y atención, admiración y empatía por la vida de las otras personas. Se trata de una transformación del posicionamiento estático y de la mirada.

Es mi deseo que este trabajo provoque esta transformación.

\section{Referencias}

BENETTO, Antonio, en DÍAZ-PAVÓN, Jesús. Enea y esparto. Artesanía campesina. Youtube. Disponible en: <https://www.youtube.com/watch?v=mFBx5Vsm2VU>. Acceso en: 5 set. 2014.

BERGER, John. Mirar. Barcelona: Gustavo Gil Editorial, 2001.

CABRERA, María Isabel. Una aproximación a la crítica artística española de los años cuarenta. Dialnet. Revista de la Facultad de Humanidades de Jaén. v. 4-5, Tomo 2, 1995-1996, pp. 79-89. Disponible en: <https://dialnet.unirioja.es/servlet/articulo?codigo=776833> Acceso en: 10 oct. 2019.

CSÍKSZENTMIHÁLYI, Mihály. Fluir. Barcelona: Kairós, 1990.

DEWEY, John. Art as Experience. New York: Minton, Balch, 1934.

DÍAZ-PAVÓN, Jesús. Enea y esparto. Artesanía campesina. Youtube. Disponible en: <https://www.youtube.com/watch?v=mFBx5Vsm2VU>. Acceso en: 5 set. 2014.

DICKINSON, Emily. Poemas. Madrid: Cátedra,1987.

DICKINSON. Emily. The gleam of an heroic act. En: JOHNSON, T.H. The complet poems of Emily Dickinson. Boston: Litle Brown, 1960.

DONOGHUE, Denis. (1983). The Arts without mystery. Boston: Litle Brown.1983.

FAJARDO, José. Jornadas de esparto en Albacete. Youtube. Disponible en: <https://www. youtube.com/watch?v=kOTNPoxsakY>. Acceso en: 24 feb. 2019.

FUSI, Juan Pablo. Un siglo de España. La cultura. Madrid/Barcelona: Marcial Pons,1999.

FREIRE, Paulo. Pedagogía del oprimido. Madrid: Siglo XXI España,1970.

GREENE, Maxine. Liberar la imaginación. Ensayos sobre educación, arte y cambio social. Barcelona: Graó, 2005.

IDIAQUEZ, Marta et al. Historia de Vida. Disponible en: <http://www.zuzenean.euskadi.eus/s68contay/es/contenidos/informacion/estadisticas_ss/es_estadist/adjuntos/proyecto_ historia_vida_memoria_final.pdf> Acceso en: 17 dic. 2015. 


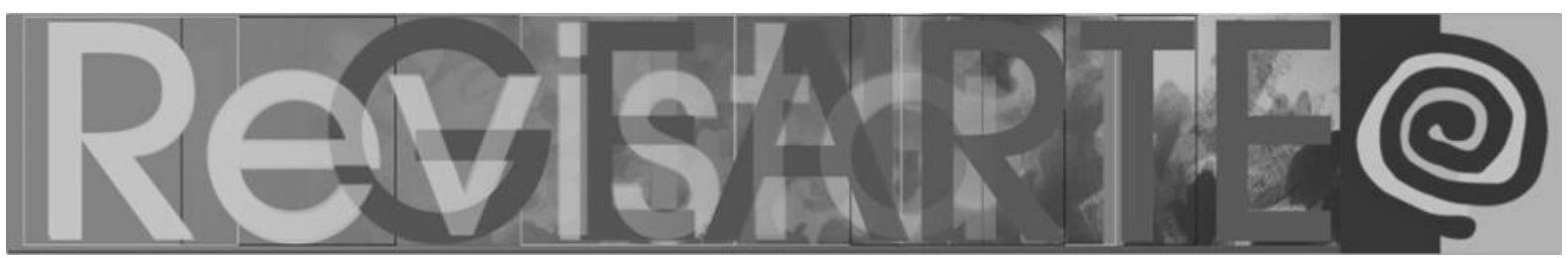

KAHNEMAM, Daniel. Pensar rápido, pensar despacio. Barcelona: Penguin Randon House, 2012.

PELTA, Raquel. La artesanía bajo el régimen de Franco. Barcelona: Fundación Historia del Diseño. Facultad de Bellas Artes. Universidad de Barcelona, 2016.

PÉREZ GÓMEZ, Ángel Ignacio. Educarse en la era digital. Madrid, España: Morata. 2012.

PÉREZ GÓMEZ, Ángel Ignacio. Pedagogías para tiempos de perplejidad. De la información a la sabiduría. Santa Fe: Homo Sapiens, 2017.

PRESTON, Paul. La Guerra Civil Española. Reacción, revolución y venganza. Barcelona: Debate, 1978.

PRESTON, Paul. El Holocausto Español. Barcelona: Debate, 2011.

RAE. Disponible en: <https://dle.rae.es/serijo>. Acceso en: 23 oct. 2019.

SMITH, John. Esparto - Alfanevada, pinceladas de nuestra memoria. Youtube. Disponible en: $<h$ ttps://www.youtube.com/watch?v=6xwifEmAJTM>. Acceso en:31 may 2016.

STAKE, Robert. Investigación con estudio de casos. Madrid: Morata, 2010.

WALKER, Alice. El color púrpura. Barcelona: Esplugues de Llobregat, 1984.

WOOLF, Virginia. Moments of Being: Unpublished Autobiographical Writings. New York: Harcourt Brace Jovanovich, 1976. (Trad. Cast.: Diario de una escritora. Barcelona: Lumen. 1982.)

WOOLF, Virginia. Un cuarto propio. Madrid: Alianza editorial, 2003.

\section{María José Delgado Corredera}

Doctoranda de la Facultad de Ciencias de la Educación de la Universidad de Málaga, España. Maestra especialista de Educación Primaria, Educación Física y Educación Musical en la Junta de Andalucía. España. Miembro del Grupo de Investigación PROCIE (HUM 619) de la Universidad de Málaga. España.

ORCID: https://orcid.org/0000-0002-6222-577X

E-mail: mjdc@uma.es / mjdc2007@gmail.com

Currículo: https://drive.google.com/file/d/1V-o8vIFVSHVc2uRim4wP3N75aAJ8uv6i/view?usp=sharing

Recebido em 15 de junho de 2020 Aceito em 19 de agosto de 2020 